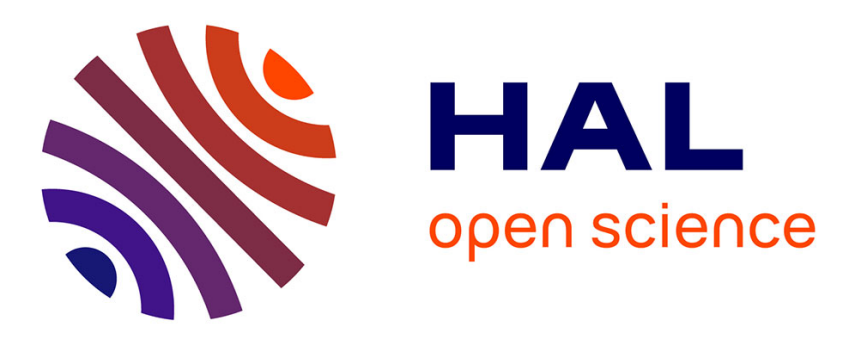

\title{
A Control Reconfiguration Strategy for Post-Sensor FTC in Induction Motor-Based EVs
}

Bekheira Tabbache, Nassim Rizoug, Mohamed Benbouzid, Abdelaziz Kheloui

\section{To cite this version:}

Bekheira Tabbache, Nassim Rizoug, Mohamed Benbouzid, Abdelaziz Kheloui. A Control Reconfiguration Strategy for Post-Sensor FTC in Induction Motor-Based EVs. IEEE Transactions on Vehicular Technology, 2013, 62 (3), pp.965-971. 10.1109/TVT.2012.2232325 . hal-00802975

\section{HAL Id: hal-00802975 https://hal.science/hal-00802975}

Submitted on 20 Mar 2013

HAL is a multi-disciplinary open access archive for the deposit and dissemination of scientific research documents, whether they are published or not. The documents may come from teaching and research institutions in France or abroad, or from public or private research centers.
L'archive ouverte pluridisciplinaire HAL, est destinée au dépôt et à la diffusion de documents scientifiques de niveau recherche, publiés ou non, émanant des établissements d'enseignement et de recherche français ou étrangers, des laboratoires publics ou privés. 


\title{
A Control Reconfiguration Strategy for Post-Sensor FTC in Induction Motor-Based EVs
}

\author{
Bekheïra Tabbache, Nassim Rizoug, Mohamed El Hachemi Benbouzid, Senior Member, IEEE, and \\ Abdelaziz Kheloui
}

\begin{abstract}
This paper deals with experimental validation of a reconfiguration strategy for sensor fault-tolerant control (FTC) in induction-motor-based electric vehicles (EVs). The proposed active FTC system is illustrated using two control techniques: indirect field-oriented control (IFOC) in the case of healthy sensors and speed control with slip regulation (SCSR) in the case of failed current sensors. The main objective behind the reconfiguration strategy is to achieve a short and smooth transition when switching from a controller using a healthy sensor to another sensorless controller in the case of a sensor failure. The proposed FTC approach performances are experimentally evaluated on a $7.5-\mathrm{kW}$ induction motor drive.
\end{abstract}

Index Terms-Electric vehicle (EV), fault-tolerant control (FTC), indirect field-oriented control (IFOC), induction motor, reconfiguration, speed control with slip regulation (SCSR).

\section{NOMENCLATURE}

$\begin{array}{ll}\text { EV } & \text { Electric vehicle. } \\ \text { FTC } & \text { Fault-tolerant control. } \\ \text { IFOC } & \text { Indirect-field oriented control. } \\ \text { SCSR } & \text { Speed Control with slip regulation. } \\ a, b, c & \text { Three-phase reference frame index. } \\ d, q & \text { Synchronous reference frame index. } \\ s,(r) & \text { Stator (rotor) index. } \\ * & \text { Reference quantity. } \\ V(I) & \text { Voltage (current). } \\ \phi & \text { Flux. } \\ \omega_{s}\left(\omega_{r}\right) & \text { Stator (rotor) electric speed. } \\ \Omega & \text { Motor speed. } \\ T & \text { Motor torque. } \\ R & \text { Resistance. } \\ L & \text { Inductance. } \\ M & \text { Magnetizing inductance. } \\ \sigma & \text { Leakage coefficient, } \sigma=1-L_{m}^{2} / L_{s} L_{r} . \\ T_{r} & \text { Rotor time constant, }\left(T_{r}=L_{r} / R_{r}\right) . \\ p & \text { Pole-pair number. }\end{array}$

Manuscript received June 28, 2012; revised October 21, 2012 and December 2, 2012; accepted December 2, 2012. Date of publication December 11, 2012; date of current version March 13, 2013. The review of this paper was coordinated by Dr. C. C. Mi.

B. Tabbache is with the University of Brest, EA 4325 LBMS, 29238 Brest, France, and also with the Ecole Militaire Polytechnique, 16111 Algiers, Algeria.

N. Rizoug is with Ecole Supérieure des Techniques Aéronautiques et de Construction Automobiles, 53061 Laval Cedex, France.

M. E. H. Benbouzid is with the University of Brest, EA 4325 LBMS, 29238 Brest Cedex 03, France (e-mail: Mohamed.Benbouzid@univ-brest.fr).

A. Kheloui is with the Ecole Militaire Polytechnique, 16111 Algiers, Algeria.

Color versions of one or more of the figures in this paper are available online at http://ieeexplore.ieee.org.

Digital Object Identifier 10.1109/TVT.2012.2232325

\section{INTRODUCTION}

$\mathbf{R}$ ECENTLY, fault-tolerant control (FTC) has begun to concern a wider range of industrial applications such as aerospace, automotive, nuclear power, manufacturing, etc. [1][3]. Indeed, a significant amount of research on FTC systems was carried out for aircraft flight control system designs [4] and for nuclear power plants [5]. Fault tolerance is no longer limited to high-end systems but also to railway [6] and automobile applications [7]. It becomes an important means to increase the reliability, availability, and continuous operation of electromechanical systems among the automotive ones [9], [10].

In the automotive context, the EV is a key application where the propulsion control depends on the availability and quality of sensor measurements. Measurements, however, can be corrupted or interrupted due to sensor faults. If some sensors are missing, the controllers cannot provide the correct control actions for the EV propulsion. Sensor FTC is therefore compulsory to maintain a minimum level of performance. In the particular case of the induction motor, as the adopted EV traction motor, many fault detection and diagnosis schemes based on vibrations and/or stator current spectrum analysis have been reported since 1980s [11]. Regarding the induction motor monitored faults, a number of FTC schemes have been proposed [9], [10], [12].

In this context, two FTC approaches could be dealt with. In the first approach, resilient control (also known as accommodation) of the drive system is adopted while retaining the same basic control strategy [13]. In this case, the controller adapts its properties to regulate the motor output as desired by the drive system even under fault conditions. In the second approach, as described in [10], the control system tolerates the faults by changing the control algorithm (also known as reconfiguration).

This paper deals with the second approach and proposes a system that adaptively reorganizes itself in the event of sensor loss or sensor recovery to sustain the best control performance given the complement of remaining sensors [7]. In particular, a specific reconfiguration mechanism is proposed to handle the smoothness of controller transitions in terms of speed and torque transients. In FTC, undesirable transients may occur during the controller reconfiguration process. These transients can cause damage to the system components. Managing or reducing these transients during a controller reconfiguration is still an open issue. Very few results are available in the literature, although several works have been done [18].

The switching problem has been previously investigated in simulations in the case of a speed sensor failure [10]. Indeed, 


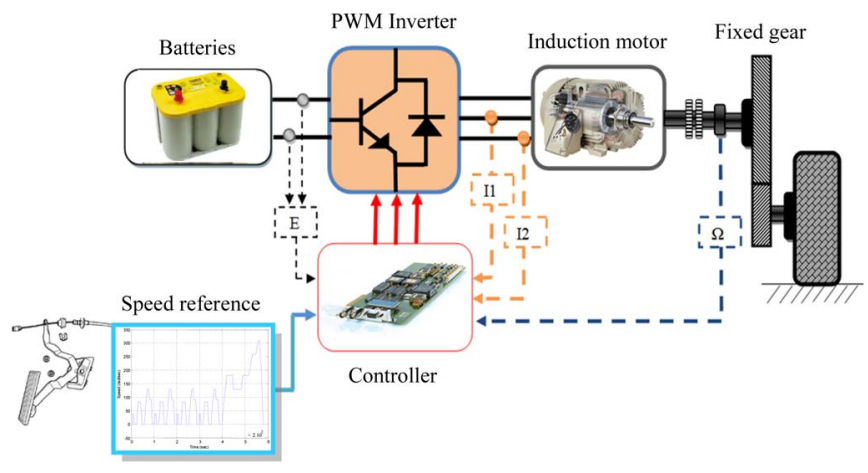

Fig. 1. Main components of an EV traction drive.

it has been suggested that controller transition could be better handled with a fuzzy approach. The system control reorganization is managed by a fuzzy decision system that ensures the transition from the encoder-based controller (sliding mode control) to the sensorless one (fuzzy control) and back to the encoder-based controller. However, the achieved transition dynamic performances were not satisfactory in terms of speed and torque ripples. In [7], the proposed system was based on four controllers to ensure the sensor FTC of an EV inductionmotor-based powertrain, for various sensors faults. In this case, the control transition smoothness depends greatly upon the rotor flux angular position in the stator reference frame. Smooth transition is achieved when the phase shift is zero or very close to zero. Unfortunately, it is very difficult to get this condition. This will lead to quite important braking torque with probably mechanical damages.

In [14], improvements have been achieved in terms of speed and torque transients. In this case, transition smoothness is achieved using a fuzzy-based approach with a contribution from both controllers (encoder and sensorless controllers). Unfortunately, practical implementation of such an approach was not possible.

This paper proposes an FTC approach using two control techniques: IFOC in the healthy case and SCSR in the case of failed current sensors. In this context, the reconfiguration mechanism philosophy is to ensure short and smooth transients when switching from a controller using a healthy sensor to another sensorless controller in case of a sensor failure, by initializing the controllers inputs/outputs at the switchover instant.

Experiments on a $7.5-\mathrm{kW}$ induction motor drive are carried out to show that the proposed sensor FTC approach is effective when using this simple and intuitive reconfiguration mechanism.

\section{Electric Vehicle Electric Drive Active FAULT-TOLERANT CONTROL}

For an EV traction drive control (see Fig. 1), fault detection and fault tolerance are important issues not only for the reliability of the drive system but for the proper operation of the vehicle following a fault as well. In particular, traction drive control depends on the availability and the quality of sensor measurements. Measurements, however, can be corrupted or interrupted due to sensor failures. If some sensors are missing, the controllers cannot provide the correct control actions for the

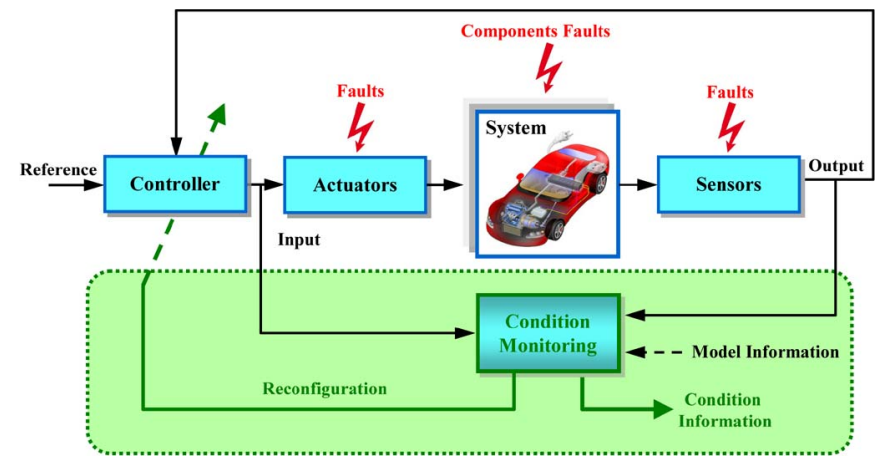

Fig. 2. Active FTC scheme.

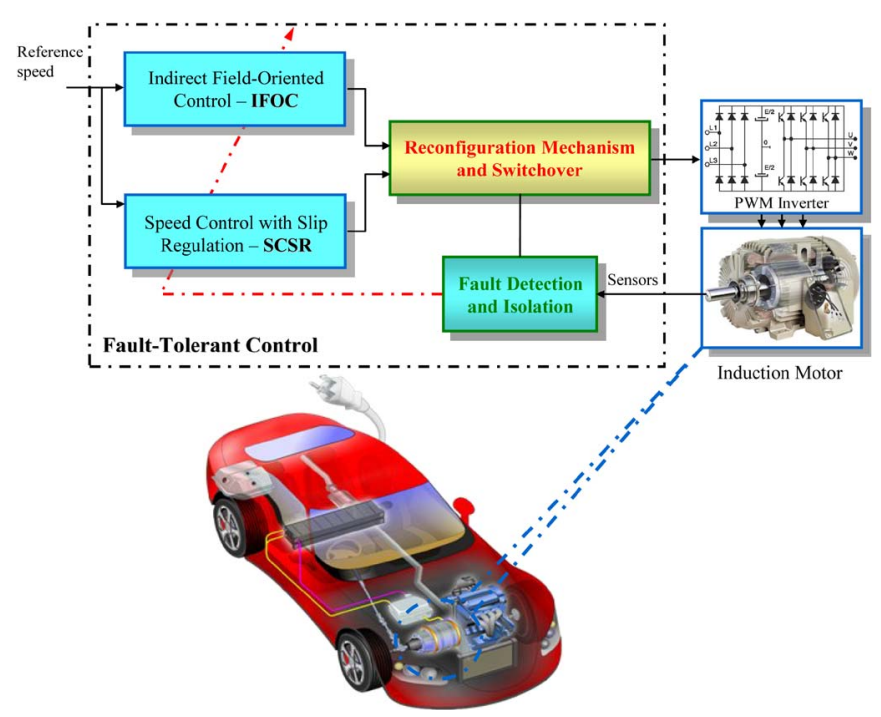

Fig. 3. FTC configuration.

EV propulsion. It is therefore compulsory to have a sensor fault detection and isolation system to improve the reliability of the electric drive. Thereafter, reconfiguration should be achieved to allow fault-tolerant operation.

In this context, an active fault-tolerant approach, as shown in Fig. 2, has been adopted. To achieve this goal, a reorganizing controller will adopt the best control methodology depending on the available feedback and operational hardware [10]. This controller comprises two parts: failure detection and fallback strategy.

While the first part monitors the status of the sensors, the second part will engage the appropriate control strategy according to the fault severity [7]. Fig. 3 shows the adopted FTC configuration using two control techniques: IFOC in the healthy case and SCSR in the case of failed current sensors. It also highlights the switchover block.

\section{A. IFOC}

IFOC aim is to decouple the flux and the torque control. To achieve this goal, the flux must be oriented on the $d$-axis in the $d-q$ frame [16], i.e.,

$$
\left\{\begin{array}{l}
\phi_{r d}=\phi_{r} \\
\phi_{r q}=0
\end{array}\right.
$$




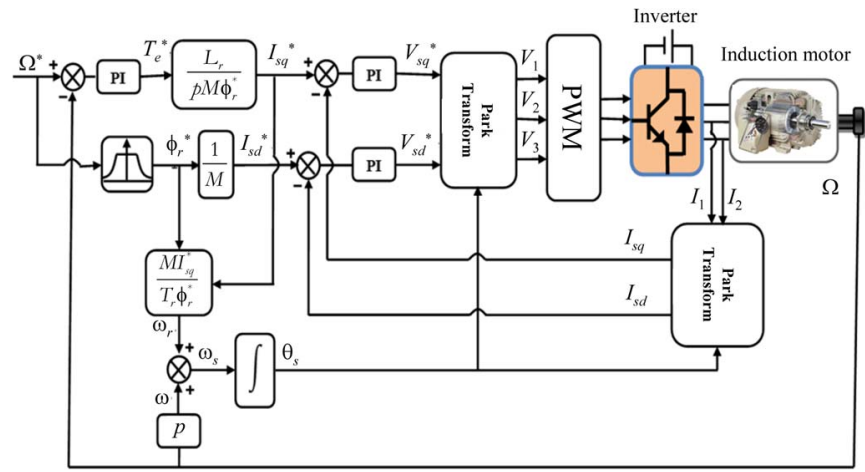

Fig. 4. IFOC scheme.

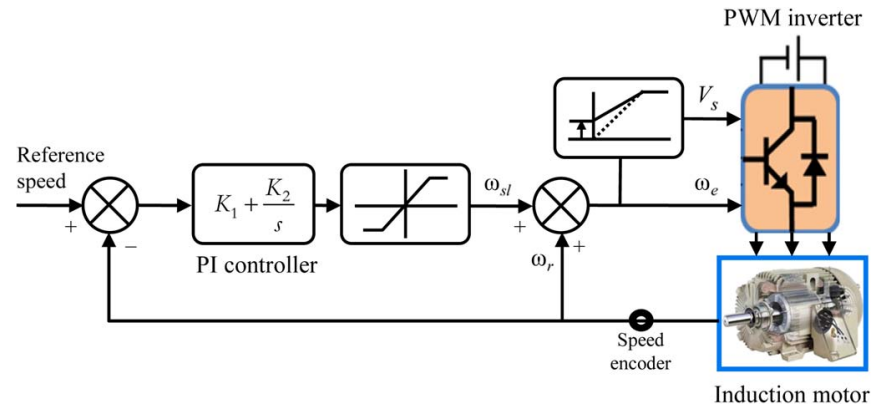

Fig. 5. Close-loop speed control with volts/hertz control and slip regulation.

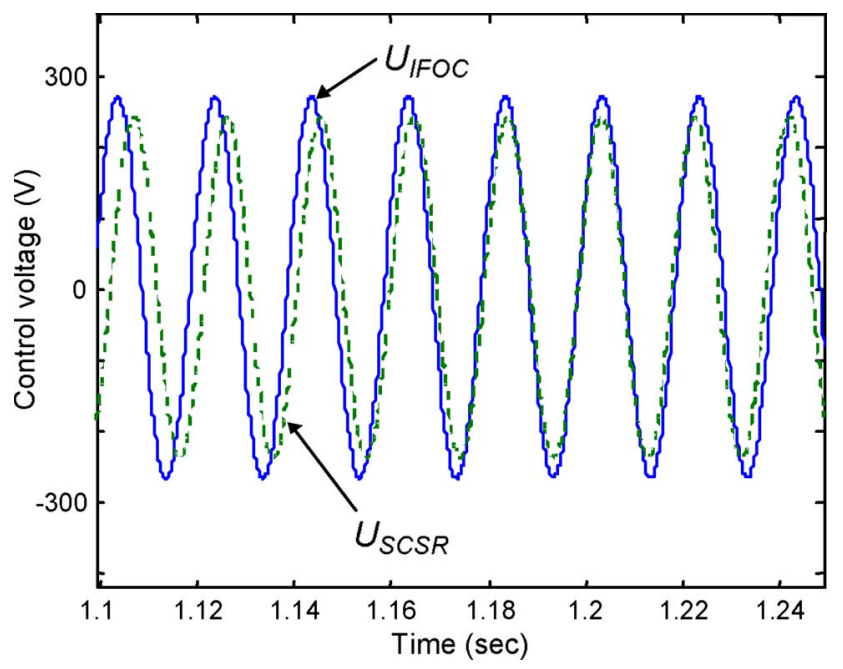

Fig. 6. Control voltages.

The induction motor model in the $d-q$ reference frame is then described by

$$
\left\{\begin{array}{l}
V_{s d}=R_{s} I_{s d}+\sigma L_{s} \frac{d I_{s d}}{d t}+\frac{M}{L_{r}} \frac{d \phi_{r}}{d t}-\omega_{s} \sigma L_{s} I_{s q} \\
V_{s q}=R_{s} I_{s q}+\sigma L_{s} \frac{d I_{s q}}{d t}+\omega_{s} \frac{M}{L_{r}} \phi_{r}+\omega_{s} \sigma L_{s} I_{s d} \\
T_{r} \frac{d \phi_{r}}{d t}+\phi_{r}=M I_{s d} \\
\omega_{s l}=\omega_{s}-\omega_{r}=\frac{M}{T_{r}} \frac{I_{s q}}{\phi_{r}} .
\end{array}\right.
$$

The steady-state motor torque can be written as

$$
T_{e}=p \frac{M}{L_{r}} \phi_{r} I_{s q}
$$

Fig. 4 shows an IFOC classical scheme [17].

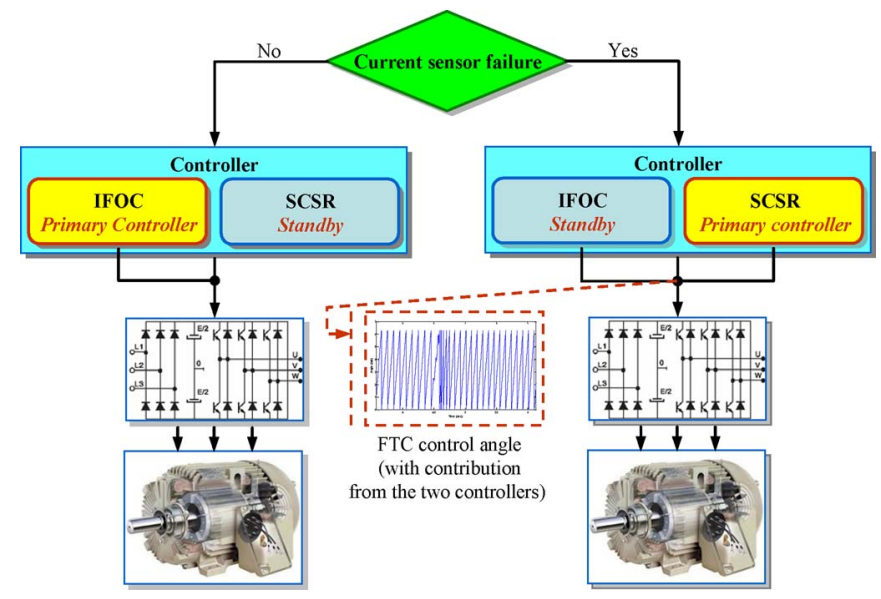

Fig. 7. Controller transition principle.

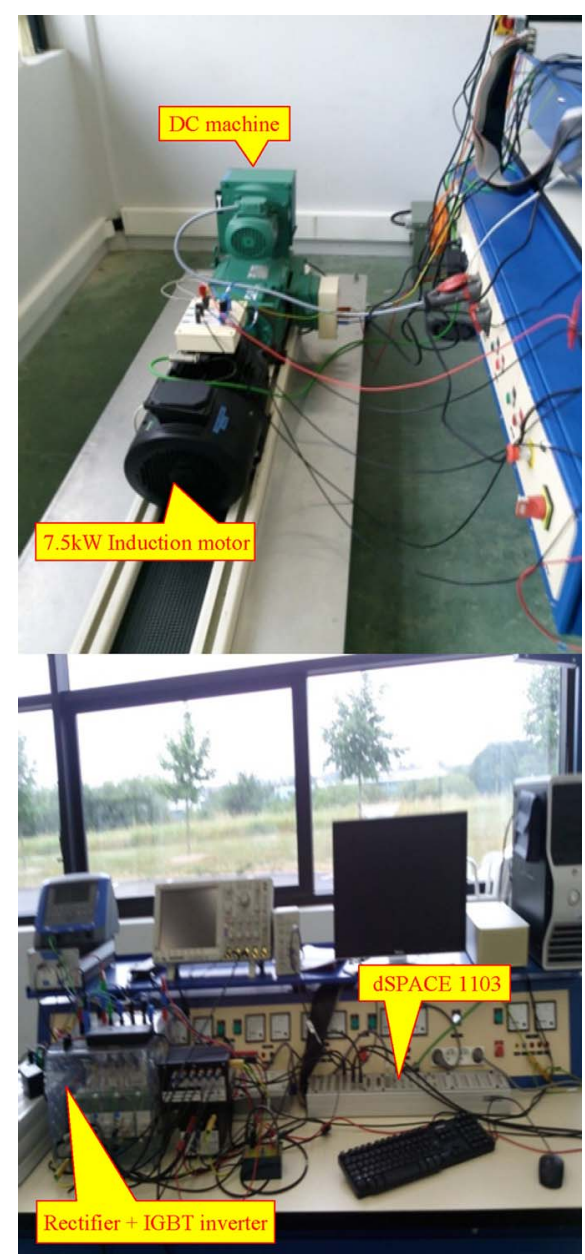

Fig. 8. Experimental test bench.

\section{B. SCSR}

This technique allows controlling the speed with slip regulation and $V / f$ control [10]. The close-loop speed control generates the reference slip $\omega_{s l}$ through a proportional-integral (PI) controller and a limiter, as shown in Fig. 5. The slip is added to the feedback speed signal to generate the frequency command. By a $V / f$ function generator, which incorporates the lowfrequency stator drop compensation, the frequency command 


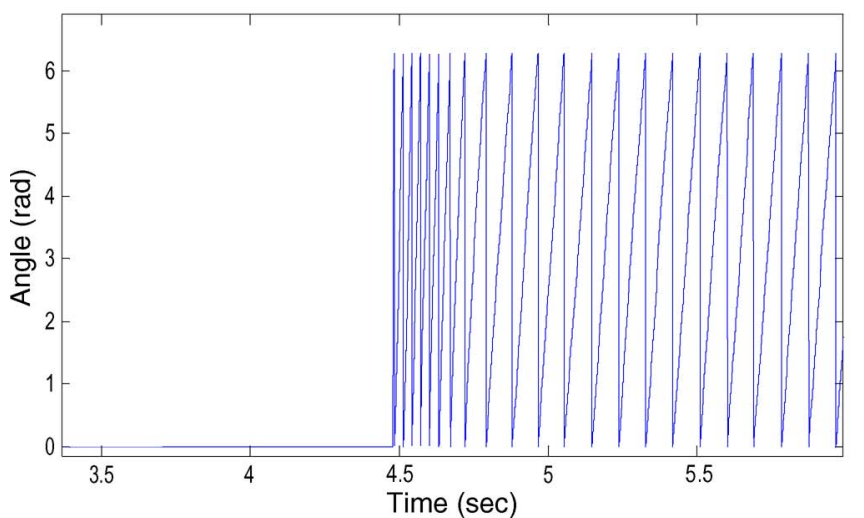

(a)

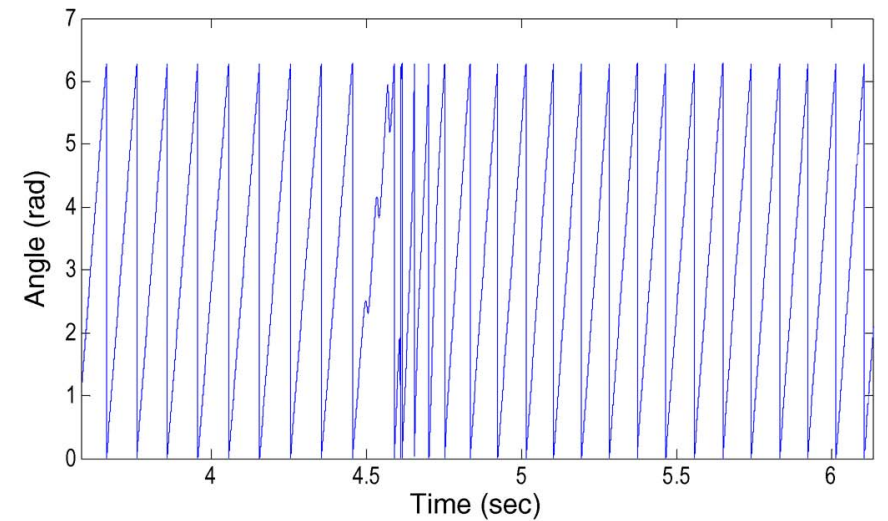

(b)

Fig. 9. Generated control angles with load torque of a $2.6 \mathrm{~N} \cdot \mathrm{m}$. (a) SCSR-generated control angle. (b) FTC control angle (with contribution from the two controllers).

generates the voltage command. In the low-slip region, the developed torque can be approximated as

$$
T_{e}=\frac{3}{2} p \frac{\phi_{m}^{2} \omega_{s l}}{R_{r}}
$$

In (4), the slip is proportional to the developed torque at constant flux. The scheme can be considered as an open-loop torque control within the speed control loop. In this loop, no feedback current signal is used.

\section{Fault Detection of Current Sensors}

To detect current sensor faults, the following equation is used:

$$
i_{\mathrm{sum}}=i_{a s}+i_{b s}+i_{c s}
$$

In the IFOC particular case, two current sensors are generally used. The third current is deduced from $i_{\text {sum }}=0$. However, for FTC purposes and for detecting current sensor failures, an additional sensor is needed.

The fault detection may be performed using a simple threshold test, i.e.,

If $\left(i_{\mathrm{sum}}>i_{\mathrm{th}}\right)$ Then (faulty current sensors)

Else (healthy sensors)

where $i_{\text {th }}$ is the current threshold.

It should be pointed out that other faults (in the power inverter or in the motor) may result in $i_{\text {sum }}$ being greater than the predefined threshold. As this paper deals with sensor failures, further investigations are therefore needed to handle misinterpretation risks in the case of multiple failures.

Additional logic and information (redundancy) can be also used to isolate the failed sensor using observers [18], [19].

\section{Reconfiguration Strategy}

The FTC main components are the induction motor controllers and the reconfiguration mechanism (transition strategy). To insure a smooth transition between the controllers, the rotor

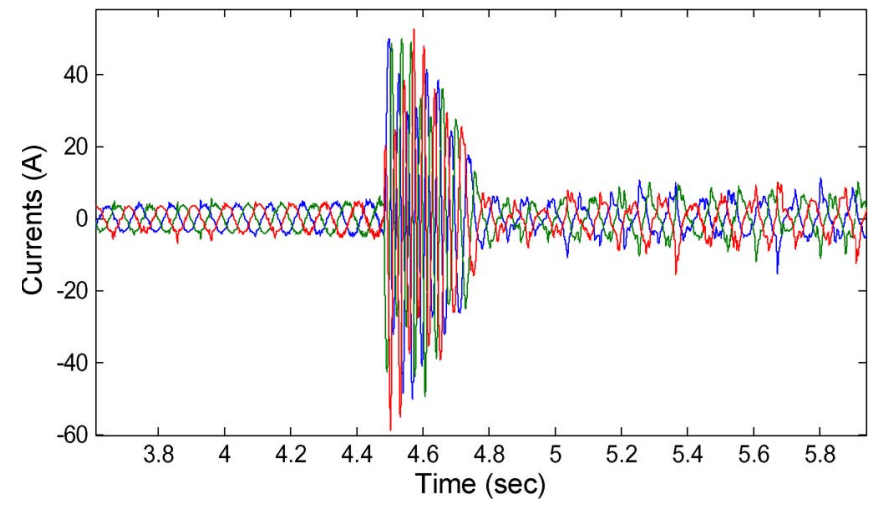

Fig. 10. Induction-motor stator currents with load torque of $2.6 \mathrm{~N} \cdot \mathrm{m}$.

flux angular position $\theta_{s}$ will be used. In the stator reference frame, it is given by [7]

$$
\theta_{s}=\int \omega_{s} d t
$$

where

$$
\left\{\begin{array}{l}
\omega_{s \_I F O C}=\frac{M I_{s q}^{*}}{T_{r} \phi_{r}^{*}}+\omega_{r} \\
\omega_{s \_ \text {SCSR }}=\left(K_{1}+\frac{K_{2}}{s}\right)\left(\omega_{r}^{*}-\omega_{r}\right)+\omega_{r} .
\end{array}\right.
$$

The reconfiguration mechanism performances will be evaluated in the case of a current sensor failure. In this context, the proposed FTC approach could be summarized by the following.

1) Before sensor failures, the two controllers are used. The IFOC is used as the primary controller, and the SCSR is kept in a standby mode. In this case, the two controllers are generating different stator electric speeds $\omega_{s}$.

2) If a sensor fails (current), the SCSR becomes the primary controller, and the IFOC is shifted to the standby mode. As the two controllers are generating different stator electric speeds $\left(\omega_{s}\right)$, if an adequate transition strategy is not used, an important braking torque with probable mechanical damages will occur. This braking torque is a direct consequence of the phase shift between control voltages [10]. 


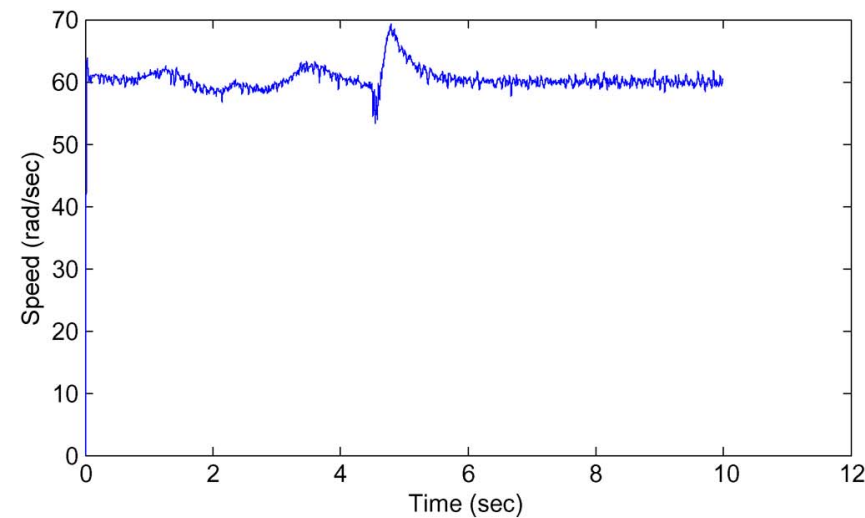

(a)

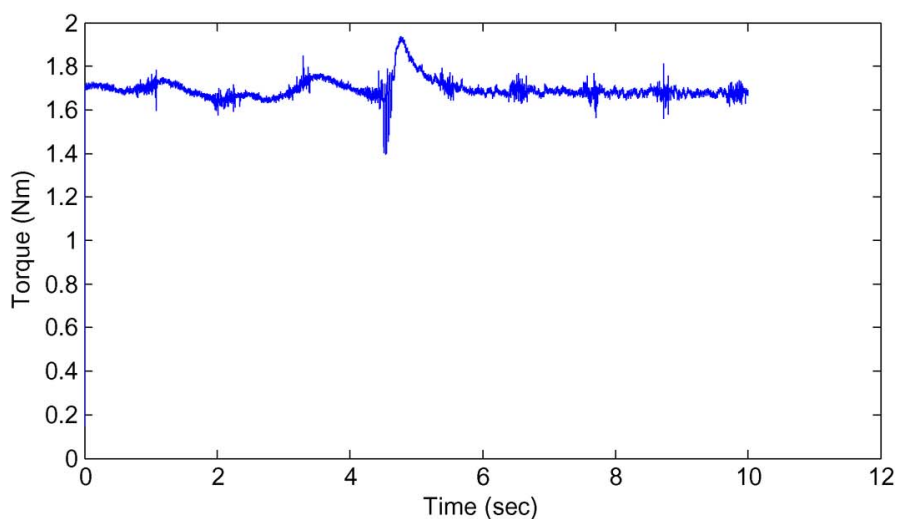

(b)

Fig. 11. Dynamics performances using the proposed reconfiguration mechanism with load torque of $2.6 \mathrm{~N} \cdot \mathrm{m}$. (a) Induction motor speed. (b) Induction motor torque.

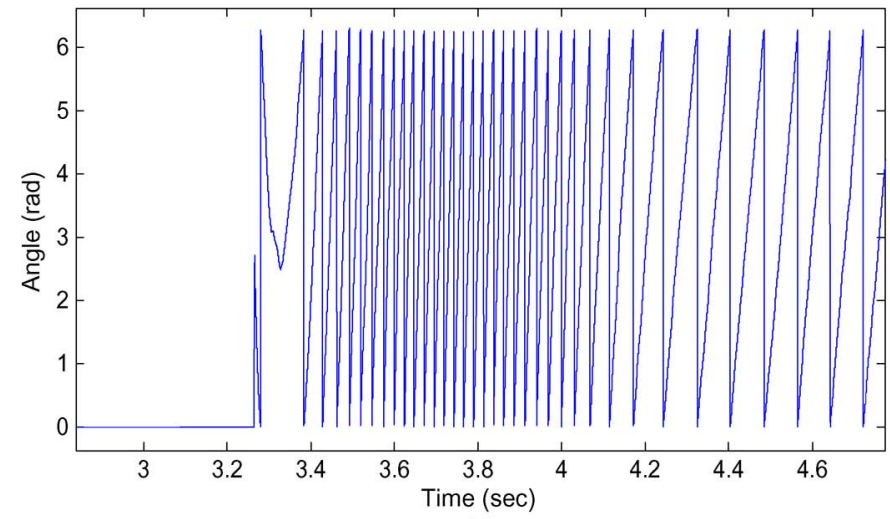

(a)

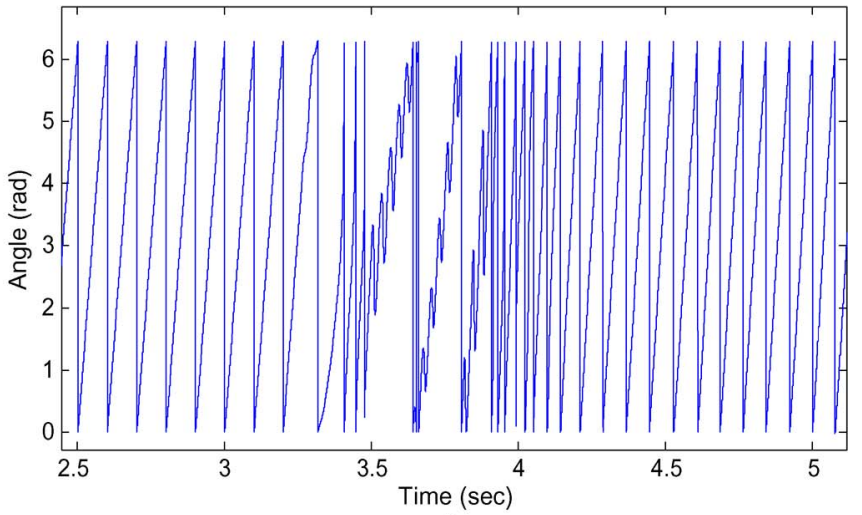

(b)

Fig. 12. Generated control angles with load torque of $5.4 \mathrm{~N} \cdot \mathrm{m}$. (a) SCSR-generated control angle. (b) FTC control angle (with contribution from the two controllers).

3) The proposed transition technique from IFOC to SCSR consists of forcing the synchronization between the two control voltages by compensating for their phase difference at the instant of controller switchover (see Fig. 6). This is achieved by initializing the second technique PI controller. In this case, a short and smooth transition should be achieved in contrary to [13], where transition of controllers were authorized when the phase shift between the controllers is zero or very close to zero. The achieved results show that forcing the synchronization of both controllers is a promising solution.

The controller transition principle is shown in Fig. 7.

\section{IMPLEMENTATION AND EXPERIMENTAL RESULTS}

\section{A. Test Bench}

The test bench used to validate the proposed active FTC approach is illustrated in Fig. 8. It is made up of a $7.5-\mathrm{kW}$ induction motor drive whose ratings are given in the Appendix.

The experimental test-bench main components are a Semikron inverter, an optical encoder attached to the motor shaft, Hall effect current sensors, and a dSPACE 1103 development board, which is interfaced to a standard PC. The load torque is generated by a dc machine coupled to the induction motor shaft.

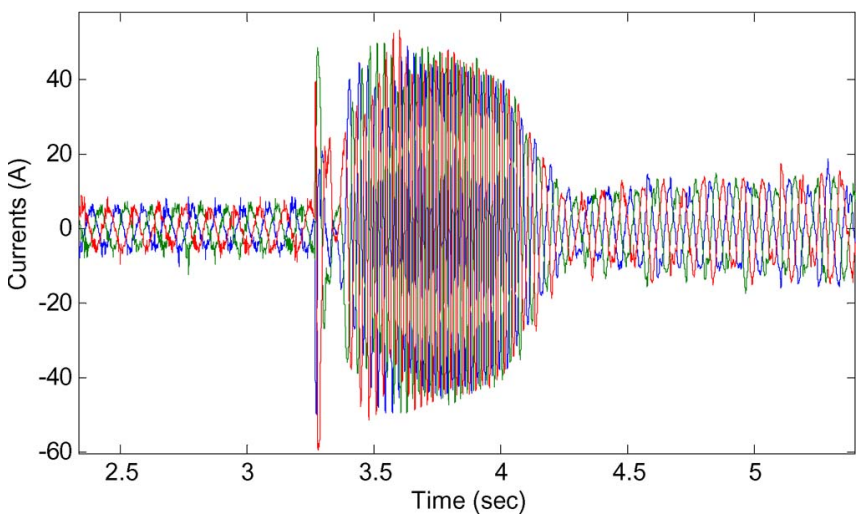

Fig. 13. Induction motor stator currents with load torque of $5.4 \mathrm{~N} \cdot \mathrm{m}$.

The continuous-time algorithm is implemented in the dSPACE board through Matlab-Simulink.

\section{B. Experimental Results}

To experimentally test the proposed reconfiguration mechanism and, therefore, evaluate the controller transition performances, the following tests have been carried out.

1) For a $2.6-\mathrm{N} \cdot \mathrm{m}$ load torque, a sensor failure has been introduced at $4.5 \mathrm{~s}$.

2) For a $5.4-\mathrm{N} \cdot \mathrm{m}$ load torque, a sensor failure has been introduced at $3.3 \mathrm{~s}$. 


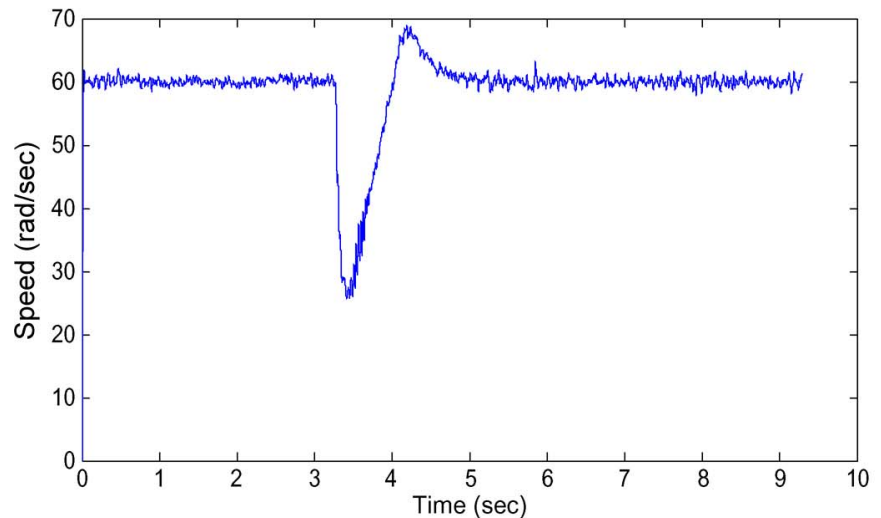

(a)

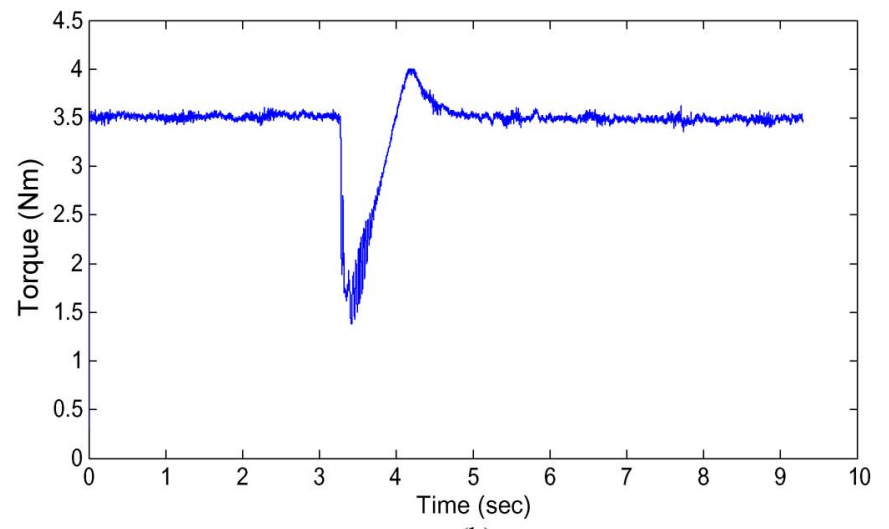

(b)

Fig. 14. Dynamics performances using the proposed reconfiguration mechanism with load torque of $5.4 \mathrm{~N} \cdot \mathrm{m}$ load torque. (a) Induction motor speed. (b) Induction motor torque.

The obtained experimental results are summarized in Figs. 9-14. It should be mentioned that the provided induction motor torque do not take into account a measurement gain of 1.5 .

Figs. 9 and 12 explicitly show the transition mechanism. Figs. 9(a) and 12(a) show how the SCSR technique control angle is compensated at the current-sensor failure time occurrence to obtain the same control angle as of the IFOC technique. Figs. 9(b) and 12(b) show thereafter the control angle (called FTC control angle) generated by the proposed control transition strategy to achieve a short and smooth transition, respectively, with load torque of 2.6 and $5.4 \mathrm{~N} \cdot \mathrm{m}$.

Figs. 10 and 13 show the induction motor stator currents, respectively, with load torque of 2.6 and $5.4 \mathrm{~N} \cdot \mathrm{m}$. In healthy condition, IFOC-based control is achieved for the induction motor. The proposed controller transition strategy (FTC control angle) allows limiting the stator current and switching to an SCSR-based control to avoid excessive stator overcurrents. Using the FTC control angle, short current transients are observed, which obviously increase with the load torque. The response times depend on the used controllers (PI coefficients).

The dynamic performances are shown in Figs. 11 and 14. These results show that, after the fault occurrence, the induction motor speed and torque swing instantaneously and thereafter quickly reach their respective set point values. In terms of speed, Figs. 11(a) and 14(a) show that smooth transitions are achieved. In terms of torque, Figs. 11(b) and 14(b) show small ripples of the motor torque in comparison with the results obtained in [10] (regarding the assigned set point values, the torque transients are quite smooth). In particular, the proposed control transition strategy allows avoiding torque negative values with the risks of mechanical damages on the motor shaft. Again, it should be noted that speed and torque ripples, and response times greatly depend on the PI coefficients of the used controllers.

The given obtained results obviously show short and smooth transients in terms of speed and torque. They experimentally prove the effectiveness of the proposed active FTC approach.

Moreover, it should be pointed out that the proposed reconfiguration mechanism (transition strategy) has brought improved transition performances over previously investigated
TABLE I

Rated Data of The TeSted Induction Motor

$7.5 \mathrm{~kW}, p=1$
$R_{S}=0.68 \Omega, R_{r}=0.39 \Omega, L_{S}=0.2225 \mathrm{H}, L_{r}=0.2268 \mathrm{H}, M=0.22 \mathrm{H}$
$J=0.01 \mathrm{~kg} . \mathrm{m}^{2}, k_{f}=0.001 \mathrm{Nms}$

approaches. Indeed, in [10], abrupt speed and torque transients are obtained (with negative values). Moreover, in terms of associated inverter power rating, this one should be selected to tolerate the transient currents (in terms of amplitude and occurrence-time). Without the proposed control transition strategy, the inverter rated power should be higher, therefore, increasing its cost.

\section{CONCLUSION}

This paper has dealt with the experimental validation of a reconfiguration mechanism (transition strategy) for sensor FTC in induction-motor-based EVs. The proposed active FTC system has been illustrated using two well-known control techniques: IFOC, in the case of healthy sensors, and the SCSR, in the case of failed current sensors. The reconfiguration strategy, whose main objective is to ensure short and smooth transients when switching from a controller using a healthy sensor to another sensorless controller in case of a sensor failure consisted of forcing synchronization between the controller voltages by compensating for their phase difference at the switchover instant.

Experimental tests on a $7.5-\mathrm{kW}$ induction motor drive show short and smooth transients in terms of speed and torque. They prove the effectiveness of the proposed active FTC approach. In particular, the experimentally validated reconfiguration strategy should be effective when used in an induction-motor-based $\mathrm{EV}$. Indeed, an EV, which is subjected to a time-varying speed reference (driving cycle), will be able to sustain sensor failure and recovery with short and smooth transients when using the proposed active FTC.

\section{APPENDIX}

See Table I. 


\section{REFERENCES}

[1] M. Bruccoleri, M. Amico, and G. Perrone, "Distributed intelligent control of exceptions in reconfigurable manufacturing systems," Int. J. Prod. Res., vol. 41, no. 7, pp. 1393-1412, May 2003.

[2] R. Isermann, R. Schwarz, and S. Stolzl, "Fault-tolerant drive-by-wire systems," IEEE Control Syst. Mag., vol. 22, no. 5, pp. 64-81, Oct. 2002.

[3] M. G. Mehrabi, A. G. Ulsoy, Y. Koren, and P. Heytler, "Trends and perspectives in flexible and reconfigurable manufacturing systems," J. Intell. Manuf., vol. 13, no. 2, pp. 135-146, 2002.

[4] M. Steinberg, "Historical overview of research in reconfigurable flight control," Proc. IMechE Part G, J. Aerosp. Eng., vol. 219, no. 4, pp. 263275, 2005.

[5] Y. Zhang and J. Jiang, "Bibliographical review on reconfigurable faulttolerant control systems," Ann. Rev. Control, vol. 32, no. 2, pp. 229-252, Dec. 2008.

[6] S. M. Bennett, R. J. Patton, and S. Daley, "Sensor fault-tolerant control of a rail traction drive," Control Eng. Pract., vol. 7, no. 2, pp. 217-225, Feb. 1999.

[7] D. Diallo, M. E. H. Benbouzid, and A. Makouf, "A fault-tolerant control architecture for induction motor drives in automotive applications," IEEE Trans. Veh. Technol., vol. 53, no. 6, pp. 1847-1855, Nov. 2004.

[8] M. Muenchhof, M. Beck, and R. Isermann, "Fault-tolerant actuators and drives-Structures, fault detection principles and applications," Ann. Rev. Control, vol. 33, no. 2, pp. 136-148, Dec. 2009.

[9] D. U. Campos-Delgado, D. R. Espinoza-Trejo, and E. Palacios, "Faulttolerant control in variable speed drives: A survey," IET Elect. Power Appl., vol. 2, no. 2, pp. 121-134, Mar. 2008.

[10] M. E. H. Benbouzid, D. Diallo, and M. Zeraoulia, "Advanced faulttolerant control of induction-motor drives for EV/HEV traction applications: From conventional to modern and intelligent control techniques," IEEE Trans. Veh. Technol., vol. 56, no. 2, pp. 519-528, Mar. 2007.

[11] M. E. H. Benbouzid, "A review of induction motors signature analysis as a medium for faults detection," IEEE Trans. Ind. Electron., vol. 47, no. 5, pp. 984-993, Oct. 2000.

[12] C. Bonivento, A. Isidori, L. Marconi, and A. Paolia, "Implicit faulttolerant control: Application to induction motors," Automatica, vol. 40, no. 3, pp. 355-371, Mar. 2004.

[13] R. Wang and J. Wang, "Fault-tolerant control with active fault diagnosis for four-wheel independently driven electric ground vehicles," IEEE Trans. Veh. Technol., vol. 60, no. 9, pp. 4276-4287, Nov. 2011.

[14] B. Tabbache, M. E. H. Benbouzid, and A. Kheloui, "On the transition improvement of EV or HEV induction motor propulsion sensor faulttolerant controller," in Proc. IEEE VPPC, Lille, France, Sep. 2010.

[15] M. Guler, S. Clements, L. M. Wills, B. S. Heck, and G. J. Vachtsevanos, "Transition management for reconfigurable hybrid control systems," IEEE Control Syst. Mag., vol. 23, no. 1, pp. 36-49, Feb. 2003.

[16] H. Rehman and L. Xu, "Alternative energy vehicles drive system: Control, flux and torque estimation, and efficiency optimization," IEEE Trans. Veh. Technol., vol. 60, no. 8, pp. 3625-3634, Oct. 2011.

[17] H. Rehman, "An integrated starter-alternator and low-cost highperformance drive for vehicular applications," IEEE Trans. Veh. Technol., vol. 57, no. 3, pp. 1454-1465, May 2008.

[18] K. S. Lee and J. S. Ryu, "Instrument fault detection and compensation scheme for direct torque controlled induction motor drives," Proc. Inst. Elect. Eng.-Control Theory Appl., vol. 150, no. 4, pp. 376-382, Jul. 2003.

[19] B. Tabbache, M. E. H. Benbouzid, A. Kheloui, and J. M. Bourgeot, "Sensor fault-tolerant control of an induction motor based electric vehicle," in Proc. ECCE EPE, Birmingham, U.K., Sep. 2011, pp. 1-8.

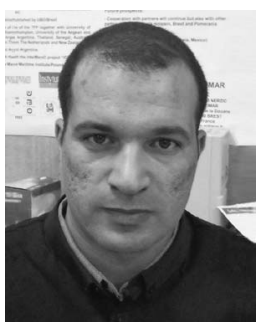

Bekheïra Tabbache was born in Chlef, Algeria, in 1979. He received the B.Sc. and the M.Sc. degrees in electrical engineering from Ecole Militaire Polytechnique, Algiers, Algeria, in 2003 and 2007, respectively. He is currently working toward the Ph.D. degree in electric-vehicle fault-tolerant control with the University of Brest, Brest, France.

Since 2004, he has been with the Department of Electrical Engineering, Ecole Militaire Polytechnique, as a Teaching Assistant.

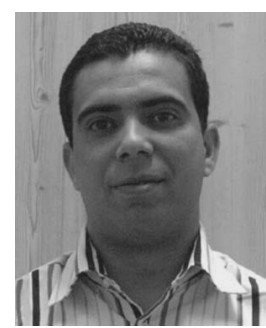

Nassim Rizoug received the Engineering degree from Ecole Polytechnique, Algiers, Algeria, in 1998 and the Ph.D. degree in electrical engineering from Ecole Centrale, Lille, France, in 2006.

Since 2007, he has been an Assistant Professor with Ecole Supérieure des Techniques Aéronautiques et de Construction Automobile, Laval, France. His research interest includes energy management and characterization of storage component in power electronic applications.

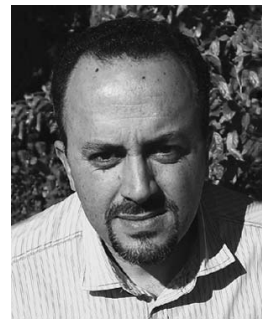

Mohamed El Hachemi Benbouzid (S'92-M'95SM'98) was born in Batna, Algeria, in 1968. He received the B.Sc. degree in electrical engineering from the University of Batna, in 1990; the M.Sc. and $\mathrm{Ph} . \mathrm{D}$. degrees in electrical and computer engineering from the National Polytechnic Institute of Grenoble, Grenoble, France, in 1991 and 1994, respectively; and the Habilitation à Diriger des Recherches degree from the University of Picardie "Jules Verne," Amiens, France, in 2000.

After receiving the Ph.D. degree, he joined the Professional Institute of Amiens, University of Picardie "Jules Verne," where he was an Associate Professor of electrical and computer engineering. Since September 2004, he has been with the University Institute of Technology of Brest, University of Brest, Brest, France, where he is currently a Professor of electrical engineering. His main research interests include the analysis, design, and control of electric machines; variable-speed drives for traction, propulsion, and renewable energy applications; and fault diagnosis of electric machines.

Prof. Benbouzid is a Senior Member of the IEEE Power Engineering, Industrial Electronics, Industry Applications, Power Electronics, and Vehicular Technology Societies. He is an Associate Editor of the IEEE TRANSACTIONS ON ENERGY CONVERSION, the IEEE TRANSACTIONS ON INDUSTRIAL ELECTRONICS, the IEEE TRANSACTIONS ON SUSTAINABLE ENERGY, and the IEEE Transactions on Vehicular Technology. He was an Associate Editor of the IEEE/ASME TRANSACTIONS ON MECHatronics from 2006 to 2009.

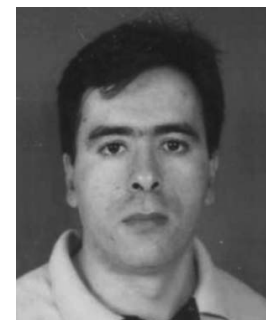

Abdelaziz Kheloui received the M.Sc. degree in electrical engineering from Ecole Nationale d'Ingénieurs et de Techniciens d'Algérie, Algiers, Algeria, in 1990 and the Ph.D. degree, also in electrical engineering, from the National Polytechnic Institute of Lorraine, Nancy, France, in 1994.

Since 1994, he has been an Associate Professor and then a Full Professor with the Department of Electrical Engineering, Ecole Militaire Polytechnique, Algiers. His current research interests include control of electrical drives and power electronics. 